\title{
Performance and Institutional Delivery Capacity of Key Road Sector
}

\author{
Agencies in Uganda. \\ Anthony G Kerali ${ }^{1}$, Yasin Olum ${ }^{2}$ \\ ${ }^{1}$ College of Engineering, Makerere University, \\ PO Box 7062, Kampala, Uganda. \\ ${ }^{2}$ College of Humanities and Social Sciences, Makerere University, \\ PO Box 7062, Kampala, Uganda.
}

\begin{abstract}
:
Sustainable development of road infrastructure can be achieved by establishing autonomous institutions. The road network must operate efficiently so that activities, operations and movements are conducted seamlessly. Competent institutions are required to achieve this goal. Unfortunately, the roads subsector in Uganda is facing numerous challenging empirics: nascent and emerging institutions, high unit rate cost of road works, traffic jams, overloading, harsh climatic conditions, varied geographic terrain, inadequate drainage, and lack of timely maintenance, lack of policy guidelines, overlapping mandates, fragmentation of planning, inadequate numbers of trained and experienced staff, lack of centralized database, shortage of financial resources, weak corporate governance, delayed procurements, over reliance on foreign expertise, and corruption. The main objective of this paper was therefore to review the institutional capability, organizational capacity and professional competence of road sector-specific agencies. The methodology used included; documentation review, meetings, interviews, questionnaires, participatory workshops, and field work. It was established that balanced economic and development status of the country was directly related to its road network. It was found that the total length of road network was $146,400 \mathrm{~km}$ of which less than 5\% was paved, comprising: national, district, urban and rural roads. It was further found that the road sector was a major driver of economic social transformation since it: links the producer with the consumer, promotes economies of scale and specialization, saves time, facilitates exploitation of natural resources, promotes industrial development, encourages agricultural linkages, facilitates defense good governance and security, promotes tourism, social and cultural activities. These were regarded as being meritorious. It is recommended that since the roads sector serves multiple purposes, but is always changing, radical but flexible solutions be continuously proposed. The main conclusion is that there is still a lot of work to be done to improve all road sector-specific institutions in the country.
\end{abstract}

Keywords: Roads, infrastructure, institutions, human resources.

\section{Introduction}

Roads represent a key driver of the transformation agenda for the majority of countries. Sustainable development of the road infrastructure can only be achieved by establishing strong semi or fully autonomous institutions dedicated to the subsector (Robinson, R; Thagasen,B, 2004; Queiroz, C; Kerali, HGR, 2010). Like with any other transport mode, the road network can be defined as comprising of fixed facilities (roads, bridges), flow entities (vehicles, motorcycles, bicycles, pedestrians), and control systems (traffic lights) that enable persons and goods to overcome the friction of geographic space (Kadyali, L; Lal, N, 2012). The system must operate efficiently so that activities, operations and movements are conducted in a timely manner. For this to be achieved capable institutions are required to serve as force multipliers. Unfortunately, the roads subsector is facing a number of challenges. While most countries in subSaharan Africa set up road specific-institutions by the early 1990s, these were only established in Uganda nearly 15 years later, after 2009. Challenging empirics include: new and emerging 
institutions, high unit rate cost of road works, traffic jams, overloading, harsh climatic conditions, varied geographic terrain, inadequate coverage, poor records, inadequate drainage, and lack of timely preventive and periodic maintenance, lack of policy guidelines, overlapping mandates, fragmentation of planning, inadequate numbers of trained and experienced staff, lack of centralized database, shortage of financial resources, weak corporate governance, delayed procurements, over reliance on foreign expertise, and corruption (Foster, V; Garmendia, C, 2009; RONET, 2015; MoWT, 2017). The main objective of this paper was therefore to review the institutional capability, organizational capacity and professional competence of road sector agencies. Institutional capability is demonstrated by how roles and responsibilities are apportioned; organizational capacity is determined by how well the institution is internally structured and resourced; professional competence is evidenced by how capable and qualified the staff are. Institutional changes are needed if the five themes of the sustainable development goals (SDGs) are to be achieved by 2030: planet, people, peace, partnership, and prosperity (NPC, 2015). The SDGs replaced the eight Millennium Development Goals (MDGs) in 2015, but the new seventeen objectives have not yet been incorporated in most country planning documents.

The methodology used included; documentation review, meetings, interviews, questionnaires, participatory workshops, and field work. The balanced economic and development status of any country is directly related to its road network (AG, 2016; Heggie, I, 2009)). An efficient road network is a force multiplier, with major positive effects. It was found that the roads sector included: the national road network, as well as district, urban and rural roads with a total length of $146,400 \mathrm{~km}$, of which only less than 5\% are paved (MoWT, 2009). Key challenges facing road sector institutions in Uganda are highlighted. It was further found that the road sector was a major driver of economic growth and social transformation since it: links the producer with the consumer, promotes economies of scale and specialization, savings in time, facilitates exploitation of natural resources, promotes industrial development, encourages agricultural linkages, facilitates defense and security, facilitates good governance, promotes tourism, social and cultural activities. It is recommended that since the roads sector serves a multitude of goals, but is always changing, radical but flexible solutions be proposed. An integrated dual approach to institutional and capacity building involving the identification of competent staff, cost effective processes, and clear communication structures are recommended. The main conclusion is that there is still a lot of work to be done to improve all road sector institutions in the country.

This paper consists of six sections. After this introductory section, the rest of the paper discusses the background, objectives, methodology, findings and recommendations, and conclusion. References are provided at the end of the paper.

\section{Background}

Uganda is a land-locked or land-linked country located in Eastern Africa. The location and highly varied terrain of the country has a direct bearing on road construction, maintenance costs, and on rates of deterioration. The county lies astride the Equator, between latitudes 10 29' South and 40 12' North, and longitudes 290 34' East and 350 0'West. It is bordered by five countries; South Sudan to the north, Kenya to the east, Congo and Rwanda to the west, and Tanzania to the south. It has an area of 241,551 $\mathrm{km} 2$, of which the land area is $200,523 \mathrm{~km} 2$. This is about the same size as Ghana and the United Kingdom. Up to $20 \%$ of the country comprises lakes and rivers. The country is the home origin of the largest fresh water lake in Africa, and second in the World, Lake Victoria (69 million km2). Lake Superior is the largest with 82 million $\mathrm{km} 2$. It is also the origin of the longest river in Earth, the River Nile $(6,695 \mathrm{~km})$. This is longer than the second longest river, the Amazon by $179 \mathrm{~km}$. The great lakes and rivers are surrounded by swampy areas. The average height above sea level is $2000 \mathrm{~m}$, with the lowest point being $600 \mathrm{~m}$ at the bottom of Lake Kyoga, and the highest being the Margarita peak in the Ruwenzori Mountains in western Uganda. The distance between north to south is about $1,100 \mathrm{~km}$, distance to the Indian Ocean is about $1,000 \mathrm{~km}$, and to the Atlantic is about $1,600 \mathrm{~km}$. The country is geographically the highest point in Africa, just like Switzerland is in Europe. Despite being astride the equator, the high and mountainous terrain provides a 
moderate climate in terms of temperature and humidity. Temperatures range between $-10 \mathrm{oC}$ at night and $330 \mathrm{C}$ during the day. Surface temperatures can reach up to $60 \mathrm{oC}$. The average daily temperature ifs about $220 \mathrm{C}$. Humidity is about $30 \%$. There are two main rainy seasons; the long and heavy rains of March to May, and the short rains of September to November. These tropical rains normally do not last longer than 3hours. The average mean rainfall is $1500 \mathrm{~mm}$ per year, with the lowest being $750 \mathrm{~mm}$ in the north east while the highest is $2250 \mathrm{~mm}$. The highest rains are recorded at Ssesse Islands in Lake Victoria and, in Gulu in northern Uganda. Karamoja region in the northeast of the country is semi-arid. These contrasting features have a direct bearing on the construction of roads in the country. They impact heavily on drainage, rain erosion, temperature, and humidity. Road sector institutions have to work around these challenges arising from the nature and environment of the surroundings...

The key functions of road sector institutions are to implement consistent and rational policy objectives, sufficient and reliable funding, effective procedures, while using modern management tools. The main institutions in Uganda include ministries, road agencies, district, urban and local authorities. The key ministries are those of: Works and Roads (MoWT), the lead ministry, Local Government (MoLG), Lands Housing and Urban Development (MoLHUD), Finance Planning and Economic Development (MoFPED) (MoWT, 2012). The main agencies include: Uganda National Roads Authority (UNRA), and the Uganda Road Fund (URF) (UNRA, 2006; URF, 2008)). Other associated agencies include: National Environment Management Authority (NEMA), Transport Licensing Board (TLB), National Road Safety Council (NRSC), District and Urban Local Governments (DULG). Generally, the goal of these institutions should be to optimize the performance of the road network over time in line with established and approved policy objectives, but within budgetary constraints. In sub Saharan Africa, out of twenty countries monitored for prevalence of good institutional practice in the road sector, it was found that three countries namely, Tanzania, Namibia and Kenya scored highest with $98 \%$ each; six countries followed with $85 \%$ each, namely Malawi, Rwanda, Madagascar, Ghana, Ethiopia, and Chad; four countries followed with $74 \%$ each, namely Zambia, Niger, Mozambique and Cameroon; two scored 58\% each Lesotho and Ivory Coast, followed by Benin at $44 \%$. Some countries like South Africa, Cape Verde and Senegal each scored $17 \%$. The rest of the countries performed even more poorly, whereby they could not even be graded (AfDB, 2011). With the present state of affairs in Uganda since 2010 on the onset of UNRA and URF, using the same yardsticks, it is estimated that Uganda could score about $46 \%$.

Managing the roads sector requires stable, longterm policy and funding frameworks. These can only develop with appropriately designed legislation and institutions. By the time of this publication, there was yet no approved roads policy for Uganda. The policy framework and objectives when developed can be holistic but should in particular focus on the following main aspects; funding, infrastructure planning and design, outsourced responsibilities, vehicle standards, driver requirements, comprehensive and consistent records keeping, accountability by leadership, human resource capacity and development, materials and equipment inventory, proper coordination, performance monitoring, and evaluation. The roads sector needs to be properly managed, following modern trends with well-established autonomous institutions in place. For this to be achieved there is an urgent need to address some basic critical issues, namely: strengthening oversight management, improving organizational hierarchy, promoting separation of responsibilities and functions, providing legally established regulatory bodies, improving on financial structures, ensuring independent auditing, promoting road user charges, establishing revenue allocation rules, introducing direct transfer of funds, and appointing user representatives on the governing boards (AfDB/WB, 2011). All these point to prevalence of institutional good practice.

The underlying challenge is that while Uganda is a resource rich country, the roads infrastructure remains a constraint for their proper exploitation. The road sector is still by far the most deficient and costly in the region. The country lags behind its development peers, and the gap continues to widen. Most of the road infrastructure is dilapidated and in urgent need of refurbishment. Due to diseconomies of scale and lack of competition, the road 
infrastructure cost remains high (UNRA, 2014). The poor state of the roads can also be attributed to several factors; the current institutional structure for management of roads is relatively new, in their formative years, and therefore not yet fully experienced and efficient; the country relies on traditional general budget allocations to fund road maintenance and rehabilitation, a formula that does not adequately deliver; current maintenance levels are insufficient to preserve the quality of the existing road network, resulting in backlogs and annual deterioration; not enough funds are reserved for preventive maintenance which would have halted further decay; prioritization of new road construction instead of maintaining current ones has exacerbated the problem, and so for every dollar not spent, three are lost; absence of other modes of roads such as waterways and rails have shifted the burden of carrying heavy freight by road; roads of petroleum products is still being done by roads, yet the suitable method should be via pipelines, thereby diminishing the lifespan of roads, and raising maintenance costs; the budgeting cycle limits the use of funds during the dry season, the season regarded as being most suitable for road construction; uncontrolled overloading, blocked drainage, and parking of heavy axle vehicles on carriageways, extremes of tropical weather, contribute to additional deterioration; there are no public private partnership (PPP) specific units or departments to develop business cases for viable and bankable major highways (brownfield projects), and proposed new alignments (greenfield projects) to attract the private sector, and foreign direct investment (FDI); projects under concessionaires are briefcase, as they move in but while being unable to obtain the stipulated funds, thus stalling projects, and wasting every ones time. Solving the road sector problems in Uganda will therefore require sustained spending under well-organized but fully or semi autonomous institutions (Postigo, A 2008; Kerali, H, 2008; Amorelli, L, 2009;). Addressing inefficiencies and closing the institutional funding gap will require capturing the correct collorary picture.

\section{Objectives}

The overall objective of this flagship paper is to provide a comprehensive, comparable and reliable sector-specific synopsis highlighting the standing and status of the key road sector institutions in Uganda. The specific objectives include providing a platform for; benchmarking relative performance and formulating a country-specific strategy in light of regional events; designing appropriate support for infrastructure reform, finance, regulation, and investment; facilitating an improved evaluation of the collective efforts by establishing a baseline of the current situation; serving as a coherent reference document on strategic issues on roads institutions; providing a vehicle for building consensus about appropriate responses and remedies; emphasizing the need for common quantitative and qualitative baseline data against which to measure future developments; improving knowledge of the road infrastructure.

The scope and scale of this paper portrays the magnitude of the challenges and provides detailed efficiency dividends from reform for overseeing the building of resilient, robust, and sustainable institutions. The paper is directed at four main categories of audiences, namely data; providers at source (line ministries, regulators, operators), collectors (consultants, analysts), managers (statistical focal persons), and users (sector agencies, specialists and financiers). While there are well over 27 road associated ministries, designated agencies and authorities dealing with different categories and levels of the road sector in Uganda, this paper focuses on the four major institutions: MoWT, UNRA, URF and KCCA. The selection was based on the roles, responsibilities and huge amount of financial resources handled by these particular institutions.

\section{Methodology}

The main methods used for the research included the following: literature review, documentation review, multiple indicator cluster survey, fieldwork (observations, interviews, inspections, measurements, and traffic counts), use of geographical information systems, applied analytical tools, use of direct performance and derived indicators, and networking and collaboration, and attending sector review workshops. These methods were used to provide a synthetic analysis and overview. The data was mainly collected at the national level but also covered the lower tiers of the road network. Collaboration and partnership mechanisms were established with major drivers of 
the sector namely, ministries, agencies, urban and local authorities.

\section{Findings and Recommendations}

\section{Main Institutions:}

The main institutions associated with the road sector in Uganda include various ministries, agencies, urban and local authorities (MDA's). While ministries were established even before independence in 1962, but only kept changing names and mandates, road sub sector agencies were recent developments, becoming operational from 2010. They are therefore relatively new autonomous or semi-autonomous institutions. They were set up by law established, and are functional with formally appointed boards of governors and staff. The lead ministry is the Ministry of Works and Roads (MoWT). Others associated with the roads sector include: Ministry of Finance Planning and Economic Development (MoFPED), Ministry of Local Government (MoLG), Ministry of Lands, Housing and Urban Development (MoLHUD). The Agencies include: Uganda National Roads Authority (UNRA), Uganda Road Fund (URF), Kampala Capital City Authority (KCCA), Engineers Registration Board (ERB), National Road Safety Council (NRSC), Roads Licensing Board (TLB), Uganda Revenue Authority (URA), National Environment Management Agency (NEMA), Uganda Police Force (UPF), and National Planning Authority (NPA). The various urban and local authorities also handle road projects. Institutional constraints found include: absent policy guidelines, fragmentation of planning, low funding levels, duplicit oversight among different ministries, absence of roads planners and economists, absence of data due to lack of a comprehensive computerized information technology database, inadequate financial resources, weak corporate governance, extensive bureaucracy especially with regard to procurements. In this paper, focus was placed on four institutions: MoWT, UNRA, URF, and KCCA. These are each discussed in turn in the sections that follow.

\section{Legal Frameworks.}

Legality of institutional set-up: in total, the government legally established twenty seven institutions: Ministries, Departments and Agencies (MDAs), in the roads sector. Legal set-up refers to
Act of Parliament, subsequent approval and operationalisation. They have both direct and indirect bearing in the formulation and implementation of the National roads master plan. These institutions fall within two broad categories; sector agencies, and associated agencies that support them either directly or indirectly.

However, some of the institutions have legal lacunas either because their legal status are fused or have no legal status. They function both as regulators and operators. This dualism in roles raises the issue of conflict of interest. Instead, the view in the agencies is that there is a need to reduce the regulatory regime which gives too much power to the Minister of Works and Roads. The argument is that the road agencies should be given more power in order to manage their affairs faster and with more flexibly. While UNRA regulated by the MoWT, as a corporation, it should function in a business-like manner. Yet in practice, it operates as a traditional civil service bureaucracy which is highly controlled by the regulator. The URF, which was meant to operate as a semi-autonomous Agency is not functioning to its full capacity because it is not fully commercialized in the business sense. It serves as a department in the MoFPED.

The case of KCCA is somewhat unique. It has different centres of power to which it has to account, namely; the Minster In-charge of Kampala, the Council chaired by the Lord Mayor, and the Executive Director of KCCA. These three centres of power have continued to generate not only political struggles but different loyalties from the Councilors and technocrats thus fragmenting the way it does business. Also, KCCA faces some practical challenges in enforcing its mandate. For instance, KCCA faces five types of legal problems on a dayto-day practical basis, namely: (a) whereas the KCCA Act allows it to manage traffic in Kampala through its Traffic Wardens, it is the UPF which is legally mandated to manage traffic in the country. The Traffic Wardens have no instrument allowing them to take any action against a traffic offender. Their powers are limited to arresting suspects and then handing them over to a Police Officer to institute charges. So, when KCCA officials issue instructions to their Traffic Wardens to implement while in the field, they are obstructed by the Police. 
(b) The Traffic Wardens and staff of KCCA are recruited by the Public Service Commission (PSC). But the same PSC objects to the idea that KCCA should have Traffic Wardens. (c) Traffic Wardens are trained by the UPF. However, after training, they want to behave as if they belong to the Police and not to KCCA. (d) A contradiction exists between the Employment Act and how the Government and KCCA operate in practice. For instance, to KCCA absenteeism from duty is spelt out as three days. But the Standing Orders of the Public Service states thirty days. This creates an enforcement problem. (e) The application of over-time by KCCA has become a problem in the sense that the nature of the work of Traffic Wardens is that they work for sixteen hours. The Employment Act calculates their over-time as follows: the hour rate is multiplied by 1.5 during week-days and during week-ends it is multiplied by two. Yet the Standing Orders of the Public Service provide that every employee of the Public Service is entitled to over-time. But it goes on to state that the rate for the over-time will be determined by the Permanent Secretary of the MoPS. And that a driver will get $30 \%$ of gross salary. Clearly, whereas the specific rate for all categories of staff is not given, it does so for only one category of employee, namely drivers. In short, KCCA finds itself in a difficult position to enforce its own laws because it contradicts with other laws in the public service.

Functionality of institutional systems and processes: road sector institutions have put in place systems and processes that are not only essential for the way they function but for the implementation of the NTMP. These institutions are functioning relatively well. The systems include; human resources, procurement, finance, management information system (MIS) or information technology (IT), and records management. In UNRA, it is working toward establishing an ERP system that integrates both the human resources and financial functions. Other institutions have either reviewed their systems and processes or are currently reviewing them.

Furthermore, KCCA has instituted two kinds of institutional and administrative practices. The institutional systems are: human resources recruitment system that follows the Public Service and PSC guidelines; capacity building system which includes an annual needs assessment, a fully developed training plan, a costed budget, and a method of selecting trainees; performance management system; a balanced scorecard which is used for measuring staff performance based on four criteria - financial key performance indicators (KPIs), customer care, internal processes, and learning and growth (or people management); and a reward and benefits system which covers payment of salaries and wages, medical benefits, wellness (a medical firm helps in staff counseling, promoting physical exercises, and medical examination), and pension for retirees. With regard to the administrative side, KCCA deals with the following: fleet management whereby each staff is expected to have roads and fuel; property management; management of both active and non-active records; and health and safety of staff. KCCA faces a number of constraints to fully utilize its systems. First, lack of funds is the biggest constraint to the effective utilization of the systems. Second, insufficient fuel affects the effectively management of the fleets of vehicles. For instance, the MoWT has given KCCA excellent and efficient equipment/machines to maintain and rehabilitate its roads. But lack of fuel is undermining their operations. Third, is slow or nonresponse by some Government MDAs towards KCCA's needs. For example, if KCCA has identified a capable person who should be recruited, the responsible Ministry or Department or Agency can take several months to respond. Such a delay certainly affects the progress of work. Fourth, is the attitude of some community members to accept and support whatever KCCA is doing. Consequently, some city inhabitants think they can do whatever they want. For example, if KCCA demarcates some areas as green zones, boda boda cyclists think they can climb onto the fenced zones and cause destruction. Fifth, some Ugandans have bad work ethic. For instance, some university graduates who get recruited in offices, including KCCA, do not want to work hard but expect to be paid salary at the end of the month.

Logistical and financial support extended to the institutions: all the road sector institutions have had generous logistical and financial support extended to them by the GoU and Development Partners (DPs). The funds come from several DPs, most notably: multilateral groups like the EU, the World Bank, 
African Development Bank (AfDB), and bilateral arrangements with the governments of Japan, China, South Korea, and Kuwait. Logistical support is extended by DPs mainly on the basis of Technical Assistance (TA). For instance, the URF gets TA from the EU. KCCA gets its support from the GoU, World Bank, Bill and Melinda Gates Foundation, LVBC, JICA from Japan, and South Korea. Counterpart funding is provided by the GoU, often with difficulty, hence causing delays.

All these initiatives have gone a long way in supplementing the budgets of these institutions and the tools they need for doing their work effectively. The support given by the GoU and DPs have had the common purpose of strengthening the roads sector management. It should be noted that although the GoU and the DPs make significant contributions to the operations of the different road sector institutions, the ideal situation should be for them to rely mainly on own revenues that they generate. It should also be noted that KCCA generates its own revenue to the tune of Shs120bn annually.

However, the support from the GoU and DPs is insufficient to sustain the activities of the respective institutions. Yet these institutions have developed the capacity to absorb the funds that are released to them. For example, the UNRA has absorptive capacity of approximately $98 \%$. Specifically, the demands of the institutions remain much higher than the support received from the GoU and DPs in terms of both recurrent and development expenditures. In UNRA, the quarterly releases $(80 \%)$ are usually less than what is budgeted for.

Communication and information flow within the institution and outside institutions: communication and information flow within the different institutional levels and among the institutions are taking place in the roads sector. These institutions have established mechanisms for clear, open and direct communication among staff members at all levels. There are also feedback mechanisms from top managers or administrators up to the lowest level and vice versa to ensure accurate, consistent and timely information sharing. The common channels of communication and information flow used by the institutions include: personal emails for follow-up of official issues, intranet, telephones, social media (i.e., Whatsapp, Twitter, and Facebook), joint review meetings with partners, steering committee meetings, sector working group (SWG), MEMOs for official circulars (formal letters are used for formal communication), Annual General Meetings (AGMs), executive meetings, and mass briefings in the case of KCCA. In URF, emails are used based on the category: top management, middle-line management and lower staff of particular officers.

The institutions asserted that they did not face any major problems with both top-down and down-up communication and information flow. Meetings are held once a week. This arrangement is meant to embed internal governance in the respective institutions. However, the institutions also face a number of challenges regarding their communication and information flow. The main challenges are twofold; first, some staff members tend to interpret information in their own way, and not the way the institutions expected. Secondly, is the culture of non-response to messages. In the UNRA, effective communication and information flow will require time to be fully established because of the restructuring that was undertaken two years ago. Indeed, the restructuring led to the recruitment of new staff that have to learn the UNRA way of doing business. Nevertheless, top-down meetings are being held every Mondays at $7.00 \mathrm{am}$. The Executive Director and Directors meet with the Heads of Department (HoD) on the last Monday of every month. The Directors then return to their respective Directorates to brief their staff on whatever has transpired in these meetings. In addition, to concretize its communication and information flow, UNRA has started a leadership program to ensure that employees understand its way of doing business across the board.

At KCCA, there are some isolated cases where it is observed that a handful of managers sometimes suppress the spread of information to other staff due to selfish motives. In addition, sometimes in a few management meetings, information is not circulated to all the members to deny them full information of what is to be discussed; the aim is to make decisions that favor those who hoard such information. Where Directors are expected to brief their staff, some do not do so. As regards communication and information flow between KCCA and its partners, 
the observation is that much as interaction is taking place, this is being hampered by four factors (i) long response time by partners toward KCCA's demands; (ii) failure by some MDAs to appreciate the use of new IT. For example, some officers are stuck in the old tradition of every business has to be transacted through hard copies; (iii) stereotyping of KCCA staff as earning huge wages and salaries. Thus, some staff in lowly paid MDAs expect KCCA officials to pay bribe before they can co-operate with them; (iv) the perception by some individuals in other MDAs that KCCA staff are proud. This causes such individuals to deny KCCA staff the information they need.

\section{Recommendations on institutional set-up:}

(a) There is a need to review the laws that constrain the effective functioning of the road sector institutions. For instance, institutions that are operating as both regulator and operator (UNRA) need urgent review. This will address the potential problem of conflict of interest; (b) UNRA should be given more powers so as to operate less bureaucratically; (c)The URF should be enabled legally to operate more commercially as a business concern than is currently the case; (d) The GoU, through the MoWT, should expedite the process of certification of the URF as well as restructure its design to enable it to operate as a semi-autonomous body; (e) Although the MoWT is well-financed other institutions face financial and logistical challenges. The GoU should plug the financial loopholes. Adequate and timely funding is a critical component for enhancing the human resource capacity building in the roads sector; (f) There is a need to recruit more staff in institutions that clearly have yawning gaps to enable them to implement their mandates effectively; (g) Where communication and information flow is still a bottleneck in these institutions, the Human Resource Departments should develop pro-active strategies of ensuring that every staff member is brought on board regarding what the institution is supposed to do. These institutions should view effective coordination of their internal and external activities as critical to the successful implementation of their strategic objectives and plans; and (h) There is a clear absence of a strong, independent, adequately resourced and functional institution to ensure effective regulation of the roads sector such as the proposed Multi-sectoral Roads Regulatory Authority (MTRA). The establishment of such a body is critical.

\section{Capacity Building and Human Resources:}

Establishment: All the legally established institutions in the roads sector have organograms. This (i.e., Board of Directors, Management and Support Staff) with a top-down and lateral structures through which management and support have clear reporting channels. The different positions have been filled using the conventional recruitment and selection processes. This implies that the institutions have clear formal internal governance structures (see appendices I-IV of the organograms of some of the institutions). The road sector institutions (UNRA, URF,) have Boards of Directors. These Boards have been found to support the activities of the institutions. In UNRA, the Board has been able to understand its transformation agenda arising from the restructuring exercise. In this sense, it has been able to drive it in its strategic direction. Its membership is comprised of people of varied backgrounds and skills, thus enabling the Board to perform as expected. It also understands UNRA's methods of work and makes quick decisions that ease day-to-day management. The members attend meetings regularly thus enabling the Board to carry out its mandate such as recruitment of staff and approval of the budget in a timely fashion.

In general, gaps in the staff establishment still exist in some institutions. These gaps adversely affect the way the institutions perform their activities as well as implement their plans. The parent MoWT has an establishment of 772, of which 552 positions are filled, and 220 are vacant. UNRA has an establishment of 1,740 of which 1,471 are filled, and 269 positions are vacant. The URF has an establishment of 35, of which 31 places are filled and 4 positions are vacant. Finally, KCCA has an establishment of 1,464 of which 392 positions are filled, leaving 1072 places vacant. This field data, obtained from each institution in August 2017, clearly shows that some institutions are doing better than others in terms of positions that have been filled in their respective establishments. The following are doing generally well; MoWT, UNRA, and URF. KCCA. In KCCA, the staff fall under the 
following categories; permanent, temporary, teachers, health workers, and casual laborers. These five categories add up to 8,000 employees. Because the GoU cannot pay for permanent staff, the temporary employees at KCCA are recruited to bridge this gap. Clearly, the situation of those institutions that are doing badly implies that they have substantial challenges.

The difficulty of filling the available positions in some of the institutions is because several of them require highly specialized skills that are in short supply and demand high salaries. In the MoWT, not all positions are filled for four main reasons: (i) inadequate wage to cater for additional recruitment; (ii) attraction and retention of staff; (iii) attrition; (iv) and retirement and non-replacement of the retirees. Of late, there is a problem of filling vacancies in the roads sector and the creation of new positions and Agencies because a recruitment cap has been imposed by the Permanent Secretary in the MoPS. Until this ban is lifted, the MoWT's hands are tied. The other critical issue is the problem of some institutions having a dual role of serving as both regulator and operator.

Design versus function: The designs or structures of the institutions are seen as capable of delivering their respective mandates. Some institutions ensure that for their designs to function effectively they have to review them periodically. In UNRA, its design was restructured in 2015. This restructuring fundamentally altered the old system whereby services were outsourced and the staffs were implementers of the outsourced services. Under the new system, the design team is in-house. Hence, the activities related to land acquisition, road construction under the Directorate of Roads and Bridges, and legal affairs are now done in-house. All these have made the process of service provision quicker and cheaper for the Authority. It remains to be seen if this will be sustainable. In URF, which has six functional areas with six managers as Heads of Department and fourteen middle line managers and twelve Logistics Assistants below them, the structure or design is not very effective to function according to its mandate. Its workload overwhelms the structure that is in place. This is why the structure is currently under review to enable it to recruit additional staff in some designated positions.
The design of KCCA is such that it has politicians (Councilors) and technocrats as its main actors. Politicians are the policy-makers and overseers of whatever takes place in the city. Technocrats are the implementers. Since politicians formulate policies which are then implemented by technocrats, they have to be well-educated, experienced and wellinformed. However, at times some of them fall below the expected standards. Hence, a lot of time is spent on political arguments than developmental issues. The other challenge KCCA is facing is that it has many auditors to attend to, for example, Internal Auditor, External Auditor/Auditor-General, MoFPED, Public Accounts Committee (PAC) of KCCA, and committee of Commissions, Statutory and State Enterprises (COSASE). The problem with these many auditors is that KCCA spends too much time responding to queries and searching for many documents over a long period of time. Ideally, an Internal Auditor and one External Auditor could suffice.

Skills gaps: the successful implementation of road agency institutional plans will require the existence of a variety of skills across the different sector institutions. The findings on the surveyed institutions clearly reveal that they possess a variety of skills ranging from highly professional/technical skills to managerial or administrative skills. Reasons for the skills gap include: (i) few specialized skills in the marketplace as compared to other technical/professional personnel like road maintenance engineers. UNRA has to rely on recruiting professionals from outside the country. However, this, too, is proving difficult due to low pay and benefits which do not attract such professionals. (ii) Inadequate wages to cater for additional recruitment, attraction and retention of staff, attrition, and retirement and non-replacement of the retirees. (iii) restructuring.

Knowledge of roles and responsibilities by institutional staff: majority of the employees of the different road sector institutions, many of whom are highly specialized, know their roles and responsibilities. Their appointment letters spell-out their roles and responsibilities. Also, other avenues are used to induct them into their jobs. In URF, as in UNRA, recruitment is extremely rigorous because 
competition is stiff. No one gets recruited in URF without the requisite qualification. URF uses external firms to recruit its personnel. In UNRA, the challenge is the extent to which individuals apply their knowledge in the different areas of specialization. Even then, all newly recruited staff need training and re-training. The institutions have clearly defined individual job descriptions and performance targets.

On remuneration, all the institutions are cognizant of the significance of the welfare of their staff to the delivery of their institution's vision, mission and goals. This is why many of the Agencies and Authorities pay their staff above average cost of living salaries and wages that can enable them to afford a good standard of living. Credit is extended to the Boards which have made commendable effort to ensure that staffs of the respective institutions are well remunerated and thereby highly motivated. The Boards regularly review staff benefits and gratuity. This high motivation also enables the staff to be retained over a long period of time in road sector institutions. At KCCA staffs know their roles and responsibilities mainly because they are given job descriptions that clearly define what is expected of them. In addition, orientation is conducted on individual job descriptions. Also, staff members sign Performance Agreements every six months in which role clarity is the main focus. Further, KCCA staff are appraised every six months through an appraisal form and feedback is given to them. Space is also provided in the appraisal form asking staff to indicate area or areas where they would want further training and re-training.

Training and re-training: existence of training and/or re-training programs is fundamental not only in the execution of the different roles and responsibilities in the roads sector institutions but their sustainability as well. The survey found out that all the institutions provide training and retraining to their employees. The institutions offer training/re-training to ensure that their staff grow and develop their individual careers. The training/retraining is done through accredited institutions, workshops and seminars, and on-the-job and off-thejob training either in the country, the region, or the rest of Africa, and overseas.
The road sector institutions conduct post-training evaluation to assess whether the requisite skills have been acquired by the trainees. In the URF, the supervisors conduct post-training evaluation after every three months to assess whether the trainee has obtained the right skills. As for KCCA, it conducts training needs assessment at two levels: (a) training needs is conducted every two years. (b) appraisal form is administered to staff every six months where space is provided asking them of potential areas for training. However, KCCA is struggling with posttraining assessment because it does not have a formal way of knowing whether a trainee has acquired the correct skills and knowledge. The training portfolio in these institutions have a training committee which can be best described as robust in the sense that they assess the training needs, examine the training programs, select the right staff to attend the training, evaluate the trainees' performance and analyze the impact of the training to the institution after training. It is recommended that they encourages staff that have completed training to make presentation to the rest of the staff to share the acquired knowledge and skills.

On the cost of training, most institutions budget for training in their Annual Budget. In UNRA, for example, the average training budget is US\$ 400,000 annually. Technical training and conferences attendance are included. For the last seven years, KCCA has had an annual budget of US\$ 1.4 million earmarked for both in-country and external training. In spite of these huge figures, they strongly believe that the funds are inadequate for training and retraining in their respective institutions.

Participation of stakeholders in policy-making, planning and M\&E of the institutions: Key stakeholders of the different road sector institutions participate in policy-making, planning and M\&E. In some cases, the participation of stakeholders in various institutions is mandatory in the sense that without such involvement, say, in stakeholder meetings, the institutions cannot do their work effectively. As for the Agencies, for example, UNRA, has adopted a pro-active strategy in relating with its stakeholders. The URF also does the same with its stakeholders. UNRA holds quarterly meetings with the MoWT to which it submits monthly Reports. In addition, it reports to the 
Auditor-General, relates with the MoFPED on budgetary issues, relates with the East African Roads Authorities Forum wherein the Executive Director (ED), who started this initiative, reaches out to other Road Authorities in the region for purposes of sharing experiences. The participation of stakeholders sometimes occurs at the strategic level. UNRA and URF reach out to the public to find out their perceptions about the roads being rehabilitated or constructed. However, stakeholder participation in other different institutions is not always smooth.

KCCA has two types of stakeholders; those with power who can positively influence or negatively hurt KCCA, and those without power. Those with power include, among others; Government, politicians, DPs, Service Commissions, Courts of Law, land owners, and employees. Those without power include, among others; teachers, health workers, and communities. These stakeholders participate in KCCA's activities differently and depending on their interests. For example, Councilors are crucial in whatever policies and byelaws KCCA wishes to enact. The communities would have been more visibly present in KCCA's Budget Conference. But the lack of allowances has kept most of them away.

Usage of policies, laws and regulations, guidelines, and standards of procedures

by the Institutions: all the institutions have policies, laws, rules and regulations, and standard operating procedures (SoPs) that guide their operations. In addition, they are managed by formally appointed officers. The essential policies range from MIS, operational regulations, human resource manuals, financial management systems, Board manuals, and management manuals. They emphasize that these provisions are being used effectively. They argue that it is because they are used that gaps are identified and then addressed. Whatever the employees of these institutions do, they have to be in line with the prescribed policies, laws, rules and regulations, guidelines, and SoPs. Or else, the institutions will experience severe instability, which is not the case with most of these institutions today. Also, the institutions ensure that each staff either has hard copies of the documents or can access the soft copies via the institution's intranet.
Nature of the relationship between the institution and other partners: relationships between the roads sector institutions and their partners can, at best, be defined as healthy. The heads of these institutions endeavor to reach out to their partners through proactive programs. This way, both parties end up cooperating and understanding each other better. It also promotes synergies across the institutions. Thus, the institutions place strong emphasis on stakeholder engagement as a critical objective because their over-riding philosophy is that they exist to serve the stakeholders. An institution like the URF has an officer/contact person responsible for stakeholder engagement.

Generally, KCCA relates well with its partners. Indeed, through its leadership, it has initiated a loose, yet to be formalized, Human Resource Forum whose members are UNRA, URF and KCCA. Its major aim is to understand what is going on in other institutions mainly from a human resource perspective. It is also about sharing information and experiences in order to advance institutional growth and development. However, this Forum has met only once. Although KCCA relates well with its partners, such as when equipment is given to KCCA by the MoWT, there are situations where the relationship is sometimes not too close. Sometimes KCCA may want to engage in the development of the surrounding districts but the respective politicians in these districts misinterpret KCCA's intentions as usurpation of their territorial integrity. This especially became noticeable during the formation of the Greater Kampala Metropolitan Area, a radius of $30 \mathrm{~km}$.

Managerial stability: leadership stability in any institution, including roads sector institutions, is crucial for the implementation of policies as well as strategic and business plans. High attrition rates of managers does not only signify that things are not right in that institution but raises the problems of policy and strategy implementation as well as the need to recruit new managers, which in and of itself, is a very costly affair. Not all the institutions experience managerial instability the same way. Nevertheless, most of them observe that most of their managers stay for long periods of time before jumping onto other institutions. As for UNRA, it 
lost only two Heads of Department before restructuring. On completion of the restructuring, managers have become more stable. So, to sustain managerial stability, institutions like the UNRA and the URF are focusing on enhancing the managerial competences of their staff and recruiting highly trained and specialized personnel who are then well remunerated and are provided excellent welfare benefits. This includes medical for the employee and his or her family, and gratuity.

Finally, the labor-force and managerial team at KCCA is stable. Those who have left have either done so due to their questionable integrity or genuine reasons such as old age or ill health. Nevertheless, KCCA has a succession plan whereby when a manager leaves someone below him or her and competent is immediately appointed. This arrangement has made KCCA to remain stable from the time it was created in 2010.

Recommendations on human resources capacity building:

(a) Institutions that have vacancies should seek the intervention of the GoU to have them filled if they are to operate optimally as well as implement their strategic plans successfully; (b) Roads sector institutions should ensure that they have training/retraining programs included in their strategic plans and budgets to enhance the human resource capacities that are central to the delivery of their mandates. New recruits who join the roads sector institutions from higher institutions of learning and have anti-work ethics should be offered induction and refresher courses as early as possible. They should also know the sanctions that can be meted out on them when they do not deliver to the expectations of their institution; (c) There is need to think of introducing a Board for KCCA which will liaise/intercede between the Council and the Minister for Kampala. This will keep both the Councilors and the Minister at bay to give technocrats the opportunity to do their business uninterrupted. The current problems affecting KCCA are more political than technical; (d) KCCA Councilors and Councilors in the District Local Governments (DLGs) who have been voted by the electorate but lack adequate education should undergo rigorous workshop and seminar trainings in, say, short tailored courses that address their roles and responsibilities. KCCA should solicit for funds from the GoU and DPs, and earmark their own resources to ensure that the sensitization workshops and seminars take place as soon as they get elected; (e) Skills that are unavailable in the roads sector institutions should be addressed in the same way as earlier suggested regarding the need to fill the established positions; (f) If all the staff in the different roads sector institutions are to apply fully their knowledge they possess then they should devise strategies that can guarantee that this happens in practice. Some remedial sanctions should be put in place to check the actions of any staff member who deviates from the institutional norm of achieving the expected outputs and outcomes; $(\mathrm{g})$ Institutions that lack resources for training/retraining should devise the necessary strategy for acquiring them from the GoU, DPs, and other partners;( h) Where necessary, stakeholders should continuously be reminded of the need to participate in policy-making, planning and M\&E of what takes place outside their own institutions; (i) The roads sector institutions that have incomplete Boards should draw the attention of the GoU on the need to constitute them if they are to function normally; ( $\mathrm{j}$ ) Given the current ban on recruitment in the public service, the roads sector institutions that have unfilled posts should approach the authorities responsible, including the MoPS, through devising workable remedies to have them filled; (k) Polices, laws and regulations, guidelines, and SoPs that are either outdated or do not support the activities of the roads sector institutions should be reviewed periodically to enable them to implement their respective mandates; (1) Where some institutions are duplicating each other's roles and responsibilities, they should be harmonized as promptly as possible; and (m) The MoPS should expedite the identification of the functional and skills gaps as well as any other requirement that shall inform the preparation of the National Roads Sector Capacity Building Master Plan (NTSCBMP). It should be emphasized that there is a need for regular skilling and re-skilling of human resources in all the institutions because of the frequent changes in technology in the roads sector.

4. Ministry of Works and Transport (MoWT): is 
the line ministry in charge of the transport sector including the roads sub-sector in the country. It is a predecessor of the Public Works Department (PWD) of the 1960's. The ministry is headed by a minister, at cabinet level, assisted by two ministers of state. Appointments, naming and renaming institutions at this level is provided for in the Constitution of the Republic of Uganda, 1995 (Chapter 7, Articles 111117). Functions and services provided by government fall under the sixth schedule. The public works entity was therefore legally established. As is the case with most countries in Africa, this current nomenclature is in itself misleading. The question here is: are works and roads in charge of the ministry, or is the ministry in charge of these functions? The ministry is responsible for the works and roads functions. The same applies to other ministries. It is therefore more appropriate to rename it as the ministry 'for' works and transport (MfWT). The same applies to other ministries. A similar institution in the United Kingdom, the originators of the English language, was once known as the Department for the Environment, but now for Transport. Similarly you have the Department for International Development (DfID). They are called departments, not ministries. Renaming them as suggested will have to be considered by the rest of Africa which is still stuck to the old terminology.

The mandate of the MoWT is to plan, develop, and maintain an economic, efficient, and effective roads infrastructure and services; to manage public works including government buildings; and to promote standards in the construction industry. Unfortunately, it was found that the ministry does not manage all public works, nor all roads infrastructure. Dams and pipelines are managed under the Ministry of Energy and Mineral Development (MEMD). The vision of the MoWT is to provide reliable and safe works, roads infrastructures and services. This conforms to the rule that a vision statement should comprise one sentence. The mission of the MoWT is to promote adequate, safe, and well maintained works and roads infrastructure and services for social economic development of Uganda. The ministry also has several key functions covering; policy, planning, programmes, monitoring and evaluation, regulations, standardization, enforcing compliance, registration and licensing, technical support, and research and development. It was found that major improvements are required in all these areas. For example, by the time of writing this paper, there was no formally approved national transport policy in place. Without a transport policy and the objectives thereof, it is difficult to formulate any long term plans. The current National Transport Master Plan (2008-23) which was rolled out in 2009, was based on a "Draft" Transport Policy of 2001. This document was never transformed into a Final National Transport Policy. It is recommended that staff be facilitated to undertake further specialized training at graduate level. The MoWT has since 2003 undergone restructuring, creating a number of institutions within its jurisdiction, separating the functions and responsibilities for road works and funding. This is more than 10 years after most subSaharan Africa had established similar institutions. It recommended that these reforms be continued, evaluated, and rolled over. The ultimate aim is to ensure that institutional best practice prevails. The parent MoWT has an establishment of 772, of which 552 positions are filled $(72 \%)$, and 220 are vacant $(28 \%)$.

5. Uganda National Roads Authority (UNRA): is the lead road agency identified and it is the current entity responsible for national roads. UNRA was fully established by an Act of Parliament in 2008 (Act 15, supplement no.5). The Act was accented to on 24th May 2008, and commenced operations on 8th June 2010. It has been in operation for nine years, one year short of a decade. The Act does not conflict with the Constitution. It does not quite assert the superiority of the Act over laws covering roads, allowing in several other actors: Ministry of Local Government, Urban Authorities, etc. It is noted that most countries in sub-Saharan Africa set up similar organizations as long ago as 1992. UNRA was preceded by the Road Agency Formation Unit (RAFU) which lasted between 2003 and 2008, and was responsible for overseeing construction and maintenance of national roads. The main function of UNRA is to be responsible for the management of the national road network, comprising $20,544 \mathrm{~km}$ of roads, 519 bridges, and 9 ferries. Bridges have been regularly washed away during rainy seasons. Ferries should have been under a yet to be set inland waterways authority. 
Typical objectives of an institution like UNRA should be to; minimize roads costs, preserve the asset value, provide and maintain accessibility, provide safe and environmentally safe infrastructure. Road management functions include; planning (setting standards, policy, long term estimates and expenditure), programming (medium term work programs), preparation (detailed project designs and work packaging and allotment), and operations (implementation of works in the field).

The financial year for UNRA is a period of 12 months ending on 30th June of the following year. It is overseen by a Board of Directors which can have between five and seven members. The Executive Director of UNRA, appointed on a five year contract renewable once, serves on the Board as an exofficio. The Executive Director is appointed by the Minister of Works and Transport. All other members of the Board are appointed by the Minister responsible for Works and Transport for a period of three years, eligible for renewal once. The main function of the board is to be responsible for the general direction and supervision of the authority. Since its establishment, while it has generally improved the stock of the national road network, and delivered positive results within only 9 years of its inception, the authority still has a lot of work to do to sustain its mandate, and clear misperceptions about the transparency, accountability and integrity of its operations. UNRA has an establishment of 1,740 of which 1,471 are filled $(85 \%)$, and 269 positions are vacant (15\%). One of the conflict areas is lack of enforcement penal enactments. Red tape has held the institution back, causing it to operate without regulations. Though nine years in existence UNRA has only recently, 14th November 2017, come up with a set of new regulations and punitive measures to protect the road infrastructure.

The regulations which come into effect in January 2018 cover hiked fines in the form of express penalties for: over-loading, encroaching on road reserves, adverts on highways, abandoning trucks on roads, repairing vehicles on the road, illegal humps, damaging roads. The lowest fines have been set at US\$100, up from USD 15. The highest fine for overloading is now USD150, 000 for vehicles above 31.5 tones. Countries like Tanzania have had these measures enforced for decades, under TANROADS.
Furthermore, the power to acquire land is subject to the Land Act, which apparently is inadequate in its current form. Prior or post compensation issues and disagreements are at the heart of the challenges. The provisions of the act need to be adapted to present realities to avoid it becoming out-of-date. A special road infrastructure committee has been set up to enforce the new measures. Since road networks have international correlations, there is always a need to keep abreast with regional and international best practices, with a view to ensuring compliance at all these levels.

Acquisition and compensation of landowners remains a big hindrance to the operations of UNRA. The land tenure system in the country is complicated. Unlike in countries like Tanzania where all land belongs to the state, the situation in Uganda is different: there is state land, municipal authority land, crown or kingdom land, ancestral land, private land, etc. Most of this land is not surveyed or titled. Negotiating with the various interests takes forever, and often ends up in court. Further, matters of land are controlled under the Ministry of Lands and Housing and the various Municipal, Kingdom or District Land Boards. The problem mainly applies to brownfield projects where expansion is sought. For new projects, or green field projects, it is recommended that they be located in virgin uninhabited areas.

The main development partners in terms of funding for roadwork's are; World Bank Group (WBG), European Union (EU), African Development Bank (AfDB), International Development Bank (IDB), Export-Import Bank (EXIM/China), BADEA-OFID, Japan International Cooperation Agency (JICA), Danish Agency for International Development (DANIDA), Korean Overseas International Cooperation Agency (KOICA), European Investment Bank (EIB). Challenges faced by the road sector institutions include; inadequate funding, unreleased budget, suspension of funding, pressure to start on new roads without commensurate funds, delayed procurement due to administrative reviews, interference in the procurement process, encroachment on road reserves, poor contract performance, lack of a permanent physical address, inadequate management of safety and social 
safeguards, corruption, old, use of obtuse and obsolete equipment. Bridges are often washed away in the rainy seasons.

Low absorption capacity of funds for new road projects has been noted. These are mainly due to; procurement delays, lengthy land acquisition processes, government's failure to raise counterpart funding, slow rate of mobilization by contractors. Allocated UGX 1.2 trillion in 2017, but by January 2018, 1 trillion had not been utilized. The consequences include: idle money, interest burden on borrowed money, loss of fiscal space.

6. Uganda Road Fund (URF): is the indentified lead entity responsible for funding certain aspects public roads. URF was fully established by an Act of Parliament in 2008 (Act 15, Supplement no.9). The Act was accented to on 31st august 2008, and become operational in January 2010, nine years ago. It is noted that most countries in sub-Saharan Africa set up similar organizations as long ago as 1994 . URF had no predecessor. It is responsible for financing the routine and periodic maintenance of public roads. It appears not to be responsible for funding capital works for construction and maintenance of national roads. Yet massive investments need to be directed to refurbish the national road network, expand the geographic coverage, and link them to regional networks, as well as to the other modes of transport.

In order to close its current road network funding gap to reach the desired total investment level, the country needs to continue increasing its spending as a percent of the GDP. This means increasing from the current $2 \%$ to over $7 \%$ over a 30 year period. Countries like China moved from $1.5 \%$ to over $9 \%$ between 1992 and 2012. The acceleration in spending can be achieved in various ways. But two alternative potential ramp-up paths or curves can be considered; (i) aggressive where spending is accelerated quickly, or (ii) a linear growth path over a 30 year period. Maintenance spending should be about $2 \%$ of GDP. The URF financial year is a period of 12 months ending on 30th June of the following year. The budgeting cycle limits the use of funs during the dry season, the season regarded as being most suitable for road construction. The URF is overseen by a Fund Management Board which has seven members, representing a broad spectrum of stakeholders; three ministries, freight forwarders, passenger road users, professional accountants and engineers. The Executive Director of URF, appointed on a five year contract renewable once, serves on the Board as an ex-officio member, acting as secretary to the board. The Executive Director is appointed by the Minister of Finance and Planning (MoFPED), although the public regards it as being under the MoWT. All other members of the Board are appointed by the Minister responsible for MoFP for a period of three years, eligible for renewal once. The main function of the board is to be responsible for the general management of the fund. Since its establishment, while it has generally improved the stock of the national road network, and delivered positive results within only eight years of its inception, the authority is yet to gain its full independence. Its perception in terms of transparency, accountability and integrity of its operations, is not in dispute. The URF has an establishment of 35 , of which 31 places are filled $(89 \%)$ and 4 positions are vacant $(11 \%)$.

7. Kampala Capital City Authority: which oversees transport in the greater Kampala Metropolitan area, was established by an Act of Parliament in 2010. Its coverage includes roads within the Capital City and greater metropolis covering neighbouring and surrounding districts of Wakiso, Mukono and Mpigi. Despite enormous progress make on the road infrastructure in the city within the past nine years, the problems found within the roads sector at KCCA are several; persistent traffic jams, fixed parking on motorable lanes, numerous motorized vehicle fleet including trucks, matatos and motor cycles (boda boda), lack of origin-destination numbering nor colour separation banding of taxis, lack of purpose high rise parking, few signal controlled intersections, overriding signal controls by police, few zebra crossings, street vending, lack of rapid bus lanes and buses, no city trains, no restricted streets for passengers only, no high charge entry routes, foreign named streets, no citywide camera controlled centre. Within the next 30 years or less, KCCA will transit from a metropolis into a megatropolis, joining the city of Jinja and the aerotropolis of Entebbe. This is about the geographic size of London, yet traffic flow there is smooth. KCCA has an establishment of 
1,464 of which only 392 positions are filled (27\%), leaving 1072 places vacant (73\%).

\section{Gaps in the Roads Sector}

8.1. Roads Research Establishment Authority Act: the country does not have a public transport research establishment or institute. Neither do they exist within academic institutions. The current Central Materials Laboratory under the MoWT located at Kireka should be upgraded to handle advanced research as well. It can be run on a commercial basis. This will involve considerable effort in enhancing its staff establishment, qualifications and mix. Similarly, a Roads Research Group should be established at the College of Engineering at Makerere University where highly qualified staff with considerable experience in the roads sector are currently based.

\subsection{Trans-Africa Highways Project: at the} continental level, the Trans African Highway (TAH) project has been proposed. The TAH has nine corridors: 1. Cairo-Dakar; 2. Algiers-Lagos; 3. Tripoli-Kinshasa-Windhoek-Cape Town; 4. CairoGaborone-Cape Town; 5. Dakar-Ndjamena; 6. Ndjamena-Djibouti; 7. Dakar-Lagos; 8. LagosBangui-Kisangani-Kampala-Mombasa; 9. BeiraLobito. The $10,269 \mathrm{~km}$ long east-west THA route 8 will pass through Kampala from Kisangani through Mpondwe border post in Kasese en-route to Nairobi and eventually Mombasa. Regional groups such as the EAC, PTA, COMESA, SADC, all of which are expected to merge under the Tripartite Free Trade Area, are expected to include these project projections in sub-regional road roads plans. The entire length will initially be two lanes, with the exception of a few four lane links. There is no visible evidence that this project has been officially integrated into the country's plans.

8.3 Integrated Infrastructure Master Plan: the country does not have a National Integrated Infrastructure Master Plan (NIIMP), so do most countries in sub-Saharan Africa, with the exception of three. The catalytic role of modern infrastructure in promoting the actualization of the sustainable development goals cannot be overemphasized. Moreover, such an integrated plan would be a blue print compendium for modernization of key complimentary infrastructure stock plans covering: works and roads, energy, information and communication technology, water supplies, agriculture, minerals, housing, security, and social services (health, education, sports, youth, labour, environment, culture, tourism). The NIIMP would be anchored on the need to project and harmonize the various sectoral infrastructure development plans into a single, comprehensive, and coherent document. The document would take into account the intra and inter-sectoral linkages. It will further engender sustainable economic growth, development, transformation and resource mobilization. However, the sector by sector approach in master planning, followed by integration, is recommended. In view of the ideal situation, one finds several difficulties with the current National Roads Plan on all fronts. This should be the responsibility of the Ministry for Finance and Planning, and more specifically the National Planning Authority (NPA) which falls under its jurisdiction. An interactive committee of field specific professionals in the different disciplines can be appointed to accomplish the task. It is clear that simple political cronyism has failed to work. There is also need to create an infrastructure delivery coordination unit to take responsibility for implementing, monitoring and evaluating plans.

9. National Transport Master Plan (NTMP): in August 2009, the first ever National Roads Master Plan was released by the Government of the Republic of Uganda. The cover page read "Ministry of Works and Transport'; National Transport Master Plan including a Transport Master Plan for the Greater Kampala Metropolitan Area (NTMP/GKMA)'. It was only in August 2009, that the Government of Uganda through the line Ministry of Works and Roads released the first ever National Roads Master Plan, covering the period 2008-2023. This represents a horizon of only fifteen years. Earlier, two five year strategic plans were rolled out in 2003, and 2007. While these represent steps in the right direction, it was noted that major challenges and drawback remain unattended to. Not much thought was given to the different modes of transportation, interaction of the nodes, their integration, nor proper projections for the future. With minimal statistical data, no clear strategic direction, absence of any solid frontal thrust from government, and no proper rationale from potential 
financiers, the plans remained inadequate. There were also no linkages with the country strategies, objectives, and an integrated infrastructure plan covering all main sectors; energy, security, industry, agriculture and the service sector.

Very limited copies of the NTMP are in circulation. Obtaining copies from the MoWT were futile, as it was widely claimed that all copies were locked up in the former headquarters at Entebbe, and therefore inaccessible. The plan was to cover the period 2008-2023, a horizon of only fifteen years. This in itself was a mistake as the time horizon of 15 years is suitable for a strategic plan but not for a master plan. The repetitions in the title are an embarrassment. Within the same heading the words Transport Master Plan are repeated. Yet it was passed by Cabinet. The title National Transport Master Plan is adequate. A Master Plan by definition is an exercise in foresight. The time horizon should be long enough to make humanly reasonable projections, and accommodate changes in technology but not so short that it is overtaken by time. Giving it fifteen years was a mistake (20082023). The correct horizon should cover a period of between 30 and 50 years. A close analysis of the contents reveals that a lot more work was required. The key objectives were to; provide a "long term 'multimodal reference framework within which consistent plans for individual modes could be developed; serve as a key input to the overall national planning process; serves as a key input to regional roads in EAC, COMESA and $\mathrm{AU}$; create framework within which investment decisions are made; establish high quality long term planning capability within the MoWT, equipped to monitor performance, periodically update, and prepare subsequent plans. Great aspirations, but progress on the ground shows that none of these objectives was ever achieved.

It is recommended that a completely new National Transport Master Plan be formulated, with a time horizon of between 30 and 50 years from the date of inception. Fortunately, by the time of preparing this paper, the European Union delegation offices in the country had initiated the process of procuring a consultant to prepare a new roads master plan. This is an indictment of the last objective that the MoWT would have an in built team to do so. Given the trilemma of a disjointed, non-integrated and obtuse challenges facing the roads sector, the need for a roads master plan, and better still, an integrated infrastructure master plan, is rising, the demand is high, and the urgency to produce such documents remains acute. An acceptable integrated transport master plan should at a minimum have the following contents; introduction, study approach or methodology, policies and objectives, assessment of the current situation, diagnosis of the existing problems, consideration of, future scenarios and options, proposed standards to be adopted, improving on existing facilities, operations and controls, considerations for safety, environmental and welfare situations, institutional issues, legal status, programme costs, investment plan, social and environmental impacts, implementation programme and performance indicators. The positive sign of the current NTMP is that it mentions the TAH, though in passing, without giving details, and connecting it to Uganda. A lot more clarification and emphasis must be placed on the $\mathrm{TAH}$, the nine routes proposed, and the investment and implementation timeline. Very little coverage is given to the pipeline mode of roads yet a $1455 \mathrm{~km}$ line is expected to be built to the port Tanga, followed by another $900 \mathrm{~km}$ one to Lamu, both on the shores on the Indian Ocean. The plan mentions the eight millennium development goals, but not the sustainable development goals. There is yet to be established a multisectoral transport regulatory authority as mentioned. An integrated, self-sustaining, robust and resilient roads system by 2050 should be the national Vision. Roads, Railways, Air, Marines, Pipelines, Ropeways, Intermodals.

\section{Conclusion}

In view of the findings covered in this paper, a resilient integrated institutional master plan that relies on accurate and well maintained comprehensive and comparable database is required for the road subsector. Capable institutions will in turn contribute towards assessing road network conditions and asset value, budgeting and prioritized investment forecasts, identification and overcoming challenging areas, country comparisons based on same framework, fast but low cost network evaluations, training, establishment of a roads research unit, and provision of sustainable solutions. Strong institutions will foresee the necessity of integrating the national road infrastructure with 
regional and sub-Saharan Africa highway projects. Institutions can be enhanced by clear mandates and strategic directions. Institutional capability, organizational capacity, and professional competence need to be strengthened to ensure their continued justification and sustainability. Institutional and capacity building in the roads sector is critical areas of concern. This reality, therefore, calls for the strengthening of the institutional and professional capabilities, and organizational capacity of all the main actors in the roads sector. Legally established institutions, some of which are main sector agencies and other agencies supporting either directly or indirectly the sector agencies, suggests that the GoU has identified their criticality. However, some of the institutions are facing legal impediments as they implement their respective mandates. Nevertheless, the institutions have developed various systems for ensuring that their processes function effectively. Also, the GoU and DPs continue to contribute financial support and logistics, where necessary, to ensure that these institutions achieve their mandates as well as implement their plans. It has also been observed that communication and information flow is occurring in all the institutions, albeit in different forms.

Furthermore, it is also noted that all the institutions have organograms that show their formal governance structures and establishments. However, gaps still exist in the establishments of all the roads sector institutions which do not augur well for their effective performance. This is in spite of the fact that the designs of the institutions are seen as capable of ensuring that they deliver outputs and outcomes expected of them. Although some of the institutions have the skilled personnel needed to achieve their mandates, others are not faring well. In spite of this shortage, most institutions report that their staff know their roles and responsibilities. The institutions also enhance the skills and knowledge of their staff through training and re-training. On another note, it is realized that stakeholders of the institutions participate in their policy-making, planning and M\&E activities. And, this is possible because all the institutions have policies, laws and regulations, guidelines, and SoPs that they effectively use for managing their institutions. Coupled with this reality is the fact that the relationship between each of the institutions and their partners is seen as generally healthy. The set-up of strong institutional structures backed by appropriate laws and policies require staff establishments of highly qualified specialists in various fields such as planners, engineers, economists, contractors, management specialists and administrators. These specialists should not only be available in the required numbers but in the right combination and time. They should also be people of high ethical standing and integrity capable of working for the common public interest.

\section{References}

[1] AG (2016). Australia Infrastructure Plan, Infrastructure Australia, Australian Government (AG), Canberra, Australia.

[2] AfDB/WB (2011). Handbook on Infrastructure Statistics. Africa Infrastructure Knowledge Program (AIKP). Africa Development Bank (AfDB)/World Bank (WB), Abidjan, Ivory Coast.

[3] Amorelli, L. (2009). Brazilian Federal Road Concessions: New Challenges in the Regulatory Framework. IBBM Issues, Minerva Program, George Washington University, Washington, D.C, USA.

[4] Heggie, I G (2009). Private Financing Options for Roads. University of Birmingham, United Kingdom.

[5] Kadyali, L R; Lal, N B. (2012). Principles and Practices of Highway Engineering. Khanna Publishers. New Delhi, India.

[6] Kerali, H G R. (2008). International trends in road management reforms. The World Bank Group, Washington, D.C, USA.

[7] MoWT (2012). Client Charter (2012/132015/16). Ministry of Works and Roads. Kampala, Uganda.

[8] MoWT (2017). Roads Sector Review Report. Ministry of Works and Roads. Kampala, Uganda.

[9] MoWT (2009). National Roads Master Plan including the Roads Master Plan for Greater Kampala Metropolitan Area. Ministry of Works and Roads. Kampala Uganda.

[10] NPC (2015). National Integrated Infrastructure Master Plan, Federal Republic of Nigeria, The Presidency, National Planning Commission (NPC), Abuja, Nigeria.

[11]Foster V; Garmendia C B (2009). Africa's infrastructure; time for transformation. Chapter 
3. Dealing with poverty and inequality. The World Bank, Washington dc

[12] Robinson, R; Thagasen, B. (2004). Road Engineering for Development. 2nd Edition. Taylor and Francis Group. London and New York.

[13]RONET (2015). Road Network Evaluation Tool. Sub-Saharan Africa Roads Policy Program (SSATP). Energy, Roads, Water Department Roads Anchor (ETWTR). World Bank, Washington DC, USA.

[14] UNRA Act (2006). Uganda National Roads Authority Act. Government Printer, Entebbe, Uganda.

[15]UNRA (2014). 5-Year Corporate Strategic Plan. Uganda National Roads Authority, Kampala, Uganda.

[16]URF Act (2008). Uganda Road Fund Act. Government Printer, Entebbe, Uganda.

[17] Postigo, A. (2008). Financing Road Infrastructure in China and India: Current Trends and Future Options. Journal of Asian Public Policy, 1:1, 71-89.

[18]Queiroz C; Kerali, H (2010). A Review of Institutional Arrangements for Road Asset Management: Lessons for the Developing World. The World Bank Group, Washington, D.C, USA.R. Caves, Multinational Enterprise and Economic Analysis, Cambridge University Press, Cambridge, 1982. (book style)

\section{Author Profile}

Anthony G Kerali received his BSc degree in Civil Engineering from Makerere University in Uganda in January 1985 . He then proceeded to practice as a professional engineer until proceeding to Loughborough University of Technology in England, on a European Union Scholarship, where he obtained an MSc in Construction in 1995. In 2002, he obtained his PhD in engineering from the University of Warwick, England, as a Commonwealth Scholar. He rapidly rose from the rank of Lecturer to Associate Professor at the College of Engineering, Makerere University. His research interests include: transportation engineering, construction management and software development. He handles several consultancies. He is widely published. He is currently serving as the Head of the department of Construction Economics and Management, as well as being a member of the University Senate.

Yasin Olum obtained his Bachelor of Arts degree from Makerere University in 1987. He then proceeded to Manchester University, England, where he was awarded an MA in Development Administration and Management. In 1998, he obtained his $\mathrm{PhD}$ in Public Administration from the University of New Castle Upon Tyne, UK. He spent sometime in 2009 as a Fulbright Scholar in the United States of America at Greensboro College, North Carolina, and at the University of Massachusetts. He currently serves as a consultant in public administration and institution building, and is widely published. He handles many consultancies. He served as the Head of the Department of Political Science and Public Administration at Makerere University in Uganda for several years before handing over. He is an academic supervisor and a member of Council at MUST. 